\title{
The innate immune response to ischemic injury: a multiscale modeling perspective
}

Elena Dimitrova', Leslie A. Caromile ${ }^{4}$, Reinhard Laubenbacher ${ }^{2,3^{*}}$ and Linda H. Shapiro ${ }^{4^{*}}$

\begin{abstract}
Background: Cell death as a result of ischemic injury triggers powerful mechanisms regulated by germline-encoded Pattern Recognition Receptors (PRRs) with shared specificity that recognize invading pathogens and endogenous ligands released from dying cells, and as such are essential to human health. Alternatively, dysregulation of these mechanisms contributes to extreme inflammation, deleterious tissue damage and impaired healing in various diseases. The Toll-like receptors (TLRs) are a prototypical family of PRRs that may be powerful anti-inflammatory targets if agents can be designed that antagonize their harmful effects while preserving host defense functions. This requires an understanding of the complex interactions and consequences of targeting the TLR-mediated pathways as well as technologies to analyze and interpret these, which will then allow the simulation of perturbations targeting specific pathway components, predict potential outcomes and identify safe and effective therapeutic targets.

Results: We constructed a multiscale mathematical model that spans the tissue and intracellular scales, and captures the consequences of targeting various regulatory components of injury-induced TLR4 signal transduction on potential pro-inflammatory or pro-healing outcomes. We applied known interactions to simulate how inactivation of specific regulatory nodes affects dynamics in the context of injury and to predict phenotypes of potential therapeutic interventions. We propose rules to link model behavior to qualitative estimates of pro-inflammatory signal activation, macrophage infiltration, production of reactive oxygen species and resolution. We tested the validity of the model by assessing its ability to reproduce published data not used in its construction.

Conclusions: These studies will enable us to form a conceptual framework focusing on TLR4-mediated ischemic repair to assess potential molecular targets that can be utilized therapeutically to improve efficacy and safety in treating ischemic/inflammatory injury.
\end{abstract}

Keywords: Ischemic injury, Boolean network, Multiscale dynamic model, TLR4, Inflammation, Macrophages

\section{Background}

Regardless of the initial insult, optimal healing of damaged tissue relies on the precise balance of proinflammatory and pro-healing processes of innate inflammation to the extent that variations in either arm can exacerbate many diseases from obesity to autoimmunity. Consequently, focusing on the mechanisms and molecules responsible for maintaining this delicate balance may identify novel regulatory nodes that are fundamental to the overall orchestration of tissue repair.

\footnotetext{
* Correspondence: Laubenbacher@uchc.edu; Ishapiro@uchc.edu

${ }^{2}$ Center for Quantitative Medicine, Department of Cell Biology, University of

Connecticut School of Medicine, Farmington, CT, USA

${ }^{4}$ Center for Vascular Biology, Department of Cell Biology, University of

Connecticut School of Medicine, Farmington 06030, CT, USA

Full list of author information is available at the end of the article
}

Dissection of the steps by which these pivotal regulatory proteins operate will increase our understanding of these interdependent responses and allow the development of more specific, effective and clinically translatable therapeutic targets to enhance the healing process and improve clinical outcomes.

Tissue damage resulting from ischemic injury invariably leads to cell death and activates the same innate inflammatory responses triggered by pathogenic organisms. The early steps of these responses proceed via a combination of shared and tissue-specific features involving numerous cytokines, signaling cascades and itineraries that drive the recruitment, differentiation and expansion of macrophages. In general, subpopulations of myeloid cells of distinct origins; resident macrophages, neutrophils, monocytes and their progeny M1 and M2 macrophages, 
orchestrate the interrelated phases of inflammation, proliferation, and remodeling [1-4]. Resting tissues harbor specific and diverse populations of 'resident' macrophages, thought to be seeded during embryogenesis, that maintain tissue homeostasis [5, 6]. In response to injury, resident macrophages produce pro-inflammatory molecules that initially attract the short-lived neutrophil population from the circulation into the wound, which are critical for initial removal of debris in preparation for repair [7-9]. Subsequently, a distinct lineage of circulating innate immune cells, the monocytes, is recruited from the blood stream to the injured tissue which then sequentially differentiate into distinct macrophage subsets (M1 and M2 macrophages, see below) $[10,11]$, Fig. 1 , potentially in response to inflammatory resolution pathways [12], molecules secreted by cells at the site [13] or other as yet undetermined changes in the physical, cellular or molecular composition of the healing tissue $[14,15]$. The monocyte-derived M1 macrophages differentiate into M2 macrophages. These subsets have opposing activities and participate in the healing process in distinct phases; M1 $[\mathrm{M}(\mathrm{IFN} \gamma)$ or classical macrophages] participate in promoting the local inflammatory response and clearing dead cells and as the microenvironmental conditions change as inflammation progresses, can differentiate/polarize into M2 macrophages [M(IL-4) or alternative macrophages] that suppress inflammation and contribute to tissue regeneration [16]. The critical role of the monocyte-derived macrophages in postischemic healing is illustrated by studies in which systemic depletion of macrophages showed markedly impaired wound healing and perfusion recovery $[17,18]$.

Macrophages and other cells constitutively display members of germline-encoded Pattern Recognition Receptors (PRRs) that recognize molecular signatures shared by invading pathogens (Pathogen-associated molecular patterns, PAMPs) and endogenous ligands released from damaged cells (Danger-associated molecular patterns, DAMPs). Upon recognition of these distress signals, PRRs rapidly activate their associated cells to eradicate the infection, remove cell debris and heal the damage. Members of the Toll-like receptor (TLR) family are predominant PRRs expressed on the cell-surface or in endosomes that stimulate the precise signal transduction and gene expression programs that guide the innate immune response in response to PAMPs and DAMPs. Ten human and twelve murine TLRs have been

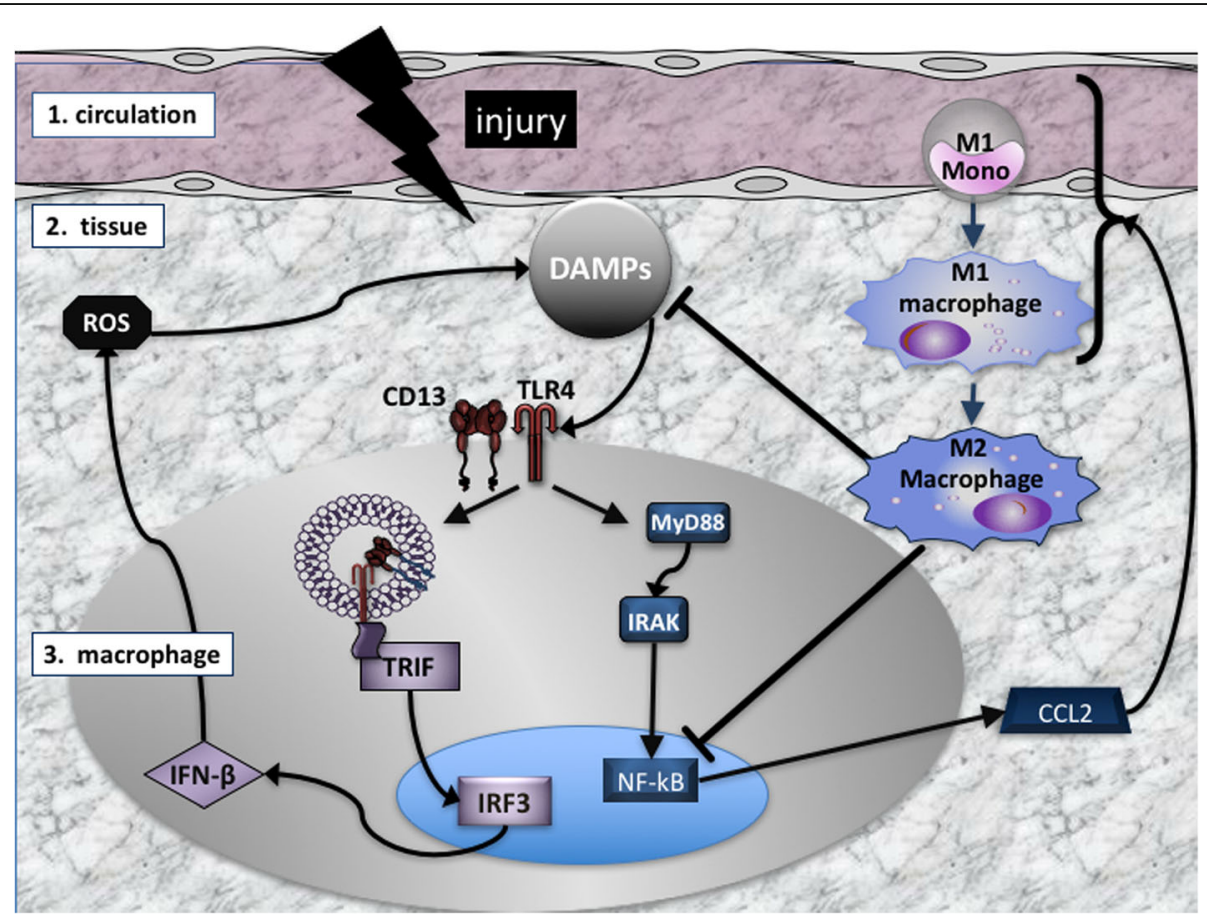

Fig. 1 Scheme of the innate immune response to injury. Injury triggers the production of DAMPs in the tissue that activate intracellular responses via TLR4, initially in the resident macrophages and later from recruited macrophages (large gray oval). TLR4 activation stimulates two intracellular pathways, the MyD88-dependent (blue rectangles), resulting in production and secretion of the chemoattractant CCL2 which serves to recruit additional immune cells from the circulation (right). In response to CCL2, M1 monocytes leave the circulation and enter the tissue where they differentiate into pro-inflammatory M1 macrophages that clear toxic debris and become activated to produce more CCL2, perpetuating the inflammatory response. TLR4 can also signal via a MyD88-independent endocytic pathway (center left) that is mediated by CD13, TRIF and IRF3. Increased activation of this pathway can lead to production of cell-damaging ROS and increased DAMPs. Finally, M1 macrophages convert into pro-healing M2 macrophages which dampen the pro-inflammatory response by blocking production of CCL2 and DAMPs, leading to resolution 
identified and are differentially activated by different ligands. For example, TLR3 detects double-stranded viral RNA, while TLR4 specifically recognizes the PAMP lipopolysaccharide displayed by gram-negative bacteria. Importantly, TLR4 also recognizes a number of DAMPs released by damaged cells and thus is critical to proper healing following ischemic injury, such as myocardial infarction, peripheral artery occlusion and stroke [19-24]. Dysregulation of these pathways triggers what are often extreme inflammatory responses resulting in further tissue damage, prolonging and exacerbating the disease [25-27]. An intricate system of control points exists to ensure the proper response consisting of positive and negative regulators, feedback loops and cross-talk among signaling pathways.

Predicting and accurately testing the outcomes of targeting one or a combination of these nodes by biological methods is challenging, prompting us to create a mathematical model that captures the mechanisms involved at the tissue as well as the intracellular scale. This model then allows the simulation of interventions at either scale. As a modeling framework we have chosen a timeand state-discrete model that captures the regulatory logic of the different mechanisms and provides a qualitative description of model dynamics without the need for quantitative kinetic and other parameters. Such models have been used extensively and there is evidence that they provide an excellent framework for a variety of applications [28-33]. Should it become necessary later to make quantitative assessments of processes, this discrete model can be converted into a continuous model with the same wiring diagram through the addition of parameters.

In recent years, a systems biology approach using mathematical modeling has been applied successfully to the study of events related to vascular injury resulting from myocardial infarction, peripheral artery occlusion and stroke. Several modeling studies have focused on the molecular level, in particular the response of growth factors, such as VEGF [34-36], the effect of ischemia/reperfusion-induced phosphometabolite availability and $\mathrm{pH}$ on ion channels and exchangers in cardiomyocytes [37] and mitigation of the negative effects of reperfusion by nitric oxide $[38,39]$. Other studies have focused on tissue-level phenomena such as hyperplasia formation [40], reperfusion-induced vasogenic edema and cerebral microvessel collapse [41], effects of tissue oxygenation [42-44], or the mechanics of platelet deposition [45, 46]. The effect of postconditioning (intermittent periods of ischemia applied during reperfusion) on the endothelial layer of blood vessels was modeled in [47], and the innate and adaptive immune response to ischemic injury in the context of organ transplant surgery is presented in [48]. To our knowledge, no general mathematical models encompassing both the tissue and intracellular scales have been proposed for the innate immune response to ischemic injury, making the model presented here novel.

\section{Methods \\ Overview of the model}

We created a dynamic mathematical model based on numerous published biological studies of TLR4 signaling in response to injury or infection in the tissue (reviewed in $[23,24])$ as well as our own studies of the role of CD13 in this response [49]. To capture the nature of the inflammatory response, we designed the model to initiate in the tissue (tissue scale) and release molecules which in turn trigger intracellular signaling mechanisms (intracellular scale), transcription and production of mediators that are secreted into the tissue to participate in a feedback loop to sustain further inflammatory cell infiltration and wound healing. In the wiring diagram of the model (Fig. 2) injury is represented by the orange triangular node, which has two possible states, 0 and 1, indicating that injury is absent, respectively present. The production of DAMPs (purple circular node) can assume three possible states, representing 'low, medium, high', on the one hand, which impacts the intracellular scale by activation of signal transduction in resident macrophages (gray oval) and which, on the other hand, produces chemoattractants (CCL2) that recruit monocytes from the circulation which differentiate into proinflammatory (M1) and then into healing (M2) macrophages once in the tissue. Each resident or recruited macrophage responds to the presence of DAMPS by activating two pathways resulting in the production and export of reactive oxygen species (ROS) and the inflammatory cytokine CCL2 (depicted as rectangular blue nodes in the model). ROS is considered as either present or absent, whereas CCL2 has three possible states, representing 'low, intermediate, high.' The M1 node in the tissue scale (black circular) can take on three states: with 0 representing the absence of macrophage activation; 1 representing the standard inflammatory response, initially as activation of resident macrophages or recruited macrophages as the response progresses; and 2 corresponding to the exaggerated presence of pro-inflammatory M1 macrophages in exacerbated injury. As the healing process progresses, M1 macrophages differentiate into pro-healing M2 macrophages (purple circular M2 node) and, among other effects, influence the intracellular pathways in the macrophages to diminish the pro-inflammatory response.

While hundreds of intracellular and extracellular molecules have been connected to the TLR4 pathway, we have limited our nodes primarily to those with published knockout studies with the understanding that we will eventually expand upon this basic model. 


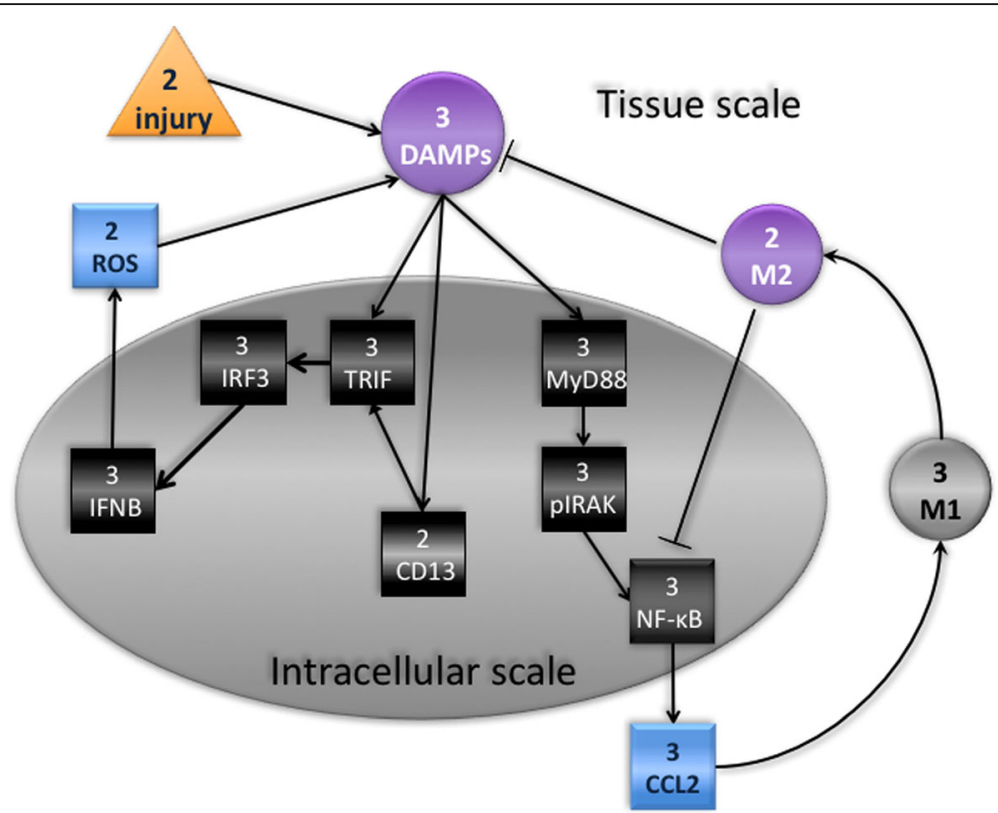

Fig. 2 Wiring diagram of the model. Injury (orange triangle) has two possible states, 0 - absent, and 1- present. The response to injury occurs at two simultaneous scales, the internal cell scale (gray oval) and the extracellular tissue scale. The tissue scale initiates with production of DAMPs (purple circle) with three states, low, medium, high, and the intracellular activation of resident macrophages via the MyD88-dependent (MyD88/ IRAK/NF-KB/CCL2) and -independent (CD13/TRIF/IRF3/IFN- $\beta$ ) pathways, resulting in recruitment of additional immune cells from the circulation (M1) and/or production of toxic ROS. The M1 node (black circle) can take on 3 states: 0, absence of macrophage activation, including resting resident macrophages; 1 standard inflammatory response- initial activation of resident macrophages and later, of recruited macrophages; and 2 exaggerated recruitment of pro-inflammatory macrophages in exacerbated injury. As the process continues, M1 macrophages become pro-healing M2 macrophages (purple circle) and dampen the pro-inflammatory response

Finally, we have made numerous assumptions to simplify the model. Specifically, we have assumed that the degree of injury is such that there is a likely probability of resolution and that injury induces uniform responses at all levels regardless of individual attributes of the tissue, cell or molecules. Similarly, we have assumed that the response to injury is singularly mediated by the TLR4 pathway and that tissue resident macrophages only participate in the initiation of the response but not at later steps. Importantly, we have solely concentrated on the monocyte/ macrophage component of inflammation and ignored the critical contribution of neutrophils to the response [7-9]. We have narrowly restricted our nodes and response outcomes within this pathway to a defined set of effectors, omitting numerous others that have been implicated in this response. The most conspicuous example of this is TLR4 itself: while we are modeling the TLR4-mediated response to injury, TLR4 is not a node in the model as it simply relays external signals to the cell interior. These assumptions and omissions can be modified and elaborated upon as the model evolves.

\section{Biological mechanisms and translation into logical rules Description of the model}

Table 1 contains a description of all the network nodes in the model, together with the possible states they can assume. The arrows in the diagram in Fig. 2 represent the dependencies between network nodes, that is, all of the regulatory inputs that each node receives from other nodes. Table 2 lists the logical rules that we have developed to translate our biological observations into qualitative effects on the different nodes. These rules are applied synchronously to all nodes at each step. (Note that the steady state values of the model are independent of the order in which the rules are applied.) When applied to the various input node values, these rules will determine the state of the node at the next time step. They are grouped according to the scale at which they operate, with the tissue scale rules listed first. The effect of these rules on the state of a particular node can be captured through a "transition table". Table 3 is an example of the transition table for the node TRIF, which depends on DAMPs and CD13. All possible input configurations for DAMPs $(0,1,2)$ and CD13 $(0,1)$ are specified in columns 1 and 2 . By applying the rules, we can assign state values to TRIF (column 3) that would logically result from these input combinations.

\section{Results}

Initiation of the tissue scale: Injury, cell death and TLR4 activation

We have focused the model on macrophage recruitment and included two mechanisms by which products of the 
Table 1 List of species, model states and biological characteristics

\begin{tabular}{|c|c|c|c|c|c|c|}
\hline \multirow[b]{2}{*}{ Species } & \multirow[b]{2}{*}{ \# States } & \multirow[b]{2}{*}{ Class } & \multirow[b]{2}{*}{ Type } & \multicolumn{3}{|c|}{ Model states } \\
\hline & & & & 0 & 1 & 2 \\
\hline Injury & 2 & external stimulus & effector & absent & present & $\ldots$ \\
\hline DAMPS & 3 & protein & effector & no injury & intermediate & high \\
\hline Ml & 3 & cell & promotes inflammation & low & intermediate & high \\
\hline M2 & 2 & cell & promotes healing & low & high & $\ldots$ \\
\hline CD13 & 2 & protein & regulator & inactive & active & $\ldots$ \\
\hline TRIF & 3 & protein & adaptor & inactive & active & hyperactive \\
\hline IRF3 & 3 & protein & transcription factor & inactive & active & hyperactive \\
\hline IFN $\beta$ & 3 & protein & cytokine & low & intermediate & high \\
\hline ROS & 2 & chemical & effector & low & high & $\ldots$ \\
\hline MyD88 & 3 & protein & adaptor & inactive & active & hyperactive \\
\hline PIRAK & 3 & protein & kinase & inactive & active & hyperactive \\
\hline NF-kB & 3 & protein & transcription factor & inactive & active & hyperactive \\
\hline CCL2 & 3 & protein & inflammatory cytokine & low & intermediate & high \\
\hline
\end{tabular}

intracellular pathways attract these effector cells to the site of injury. Initially, in response to tissue injury, dead and dying cells release endogenous intracellular proteins, thus providing molecular 'danger' signals or DAMPs (Table 2, rules \#2-6, [19, 21]). The extracellular DAMPs activate tissue-resident macrophages [50] and trigger the intracellular signaling cascades of the inflammatory response that serve to initially recruit circulating macrophages to the site of injury to repair damaged tissue, remove dead cells and heal the wound. Paradoxically, failure to activate this response results in further damage due to inflammatory hyper-activation by the toxic accumulation of apoptotic cell debris, whereas excessive activation can also lead to dysregulated inflammation and further tissue damage. Therefore, tight control of the response to injury is imperative for a balanced and effective immune response.

\section{Intracellular signaling pathways from the plasma membrane and endosome}

Once activated, the TLR4 response to DAMPs is somewhat unique in that it activates two distinct intracellular signaling pathways from different locations. These can be distinguished by their requirement for the intracellular adaptor protein MyD88. MyD88-dependent signaling originates from the plasma membrane, inducing the classic pro-inflammatory cascade [51-53]. Alternatively, MyD88-independent, TRIF-mediated signals originate from intracellular endosomal vesicles, activation of transcription and production of proteins that generally promote the adaptive immune response [51]. The importance of controlling these signaling pathways is illustrated by the induction of severe pathologies resulting from overstimulation of the pathway or the production of deleterious reactive oxygen species (ROS) by excessive levels of MyD88-independent signaling. ROS release into the tissue damages cells, increasing tissue DAMPs and amplifying the immune response. Finally, systemic depletion of macrophages severely impairs wound healing $[54,55]$, suggesting that independent but overlapping regulatory nodes exist [56].

\section{MyD88-dependent signal transduction from the plasma membrane}

DAMPs recruit MyD88 to the plasma membrane to result in the phosphorylation of IRAK (Interleukin-1 receptorassociated kinase 1) to pIRAK, which then disassociates from MyD88 to perform a series of additional interactions leading to activation and nuclear localization of the NF- $\mathrm{kB}$ (nuclear factor kappa enhancer of $\mathrm{B}$ cells) transcription factor complex. In the nucleus, NF- $\kappa B$ induces the production of various inflammatory cytokines, such as CCL2, TNF- $\alpha$, IL-12 and IL- $1 \beta$. We have chosen to focus on CCL2, but the other cytokines and their regulators can be added in the future. These factors are secreted from the cell to attract other inflammatory cells via their cognate receptors, ultimately impacting the tissue model by recruiting more monocytes (that become macrophages), which can either facilitate healing in a balanced state or escalate tissue damage when dysregulated. The amplitude of these components is determined largely by the intensity of DAMPs. We have assigned three levels of activation to MyD88, IRAK, NF-kB and CCL2 $(0,1,2)$ Table 2, Rules \#20-24.

MyD88-independent signal transduction from endosomes Alternatively, ligand binding to TLR4 also induces translocation of TLR4/ligand from the plasma membrane into 
Table 2 Tissue Scale Rules

\begin{tabular}{|c|c|c|c|}
\hline \multirow{2}{*}{\multicolumn{2}{|c|}{$\frac{\text { Rule }}{\mathrm{CCL} 2 \text { and } \mathrm{ROS}<- \text { from intracellular model }}$}} & \multirow[t]{2}{*}{ Literature support } & \multirow[t]{2}{*}{ Relevant references } \\
\hline & & & \\
\hline 1 & $\operatorname{Injury}(2)^{*}=0$ if $\mathrm{M} 2=1$ and previous injury $=1$ & M2 macrophages will resolve tissue damage due to injury. & {$[1,82-84]$} \\
\hline 2 & DAMPs (3) $=0$ if Injury $=0$ AND ROS $=0$ regardless of M2 & DAMPs are generally not accessible without tissue damage. & {$[85,86]$} \\
\hline 3 & DAMPs $=0$ if (Injury $\left.=1 X^{\prime} R^{* *} R O S=1\right)$ and $M 2=1$ & $\begin{array}{l}\text { M2 macrophages can completely resolve damage due to } \\
\text { either injury or ROS. }\end{array}$ & [85-92] \\
\hline 4 & $\begin{array}{l}\left.\text { DAMPs }=1 \text { if (Injury }=1 X^{\prime} O R^{* *} \text { ROS }=1\right) \text { and } M 2= \\
0 \text { unless previous DAMPs }=2\end{array}$ & $\begin{array}{l}\text { Lack of M2 macrophages leads to increased tissue damage in } \\
\text { response to injury or ROS unless overwhelming damage. }\end{array}$ & [85-92] \\
\hline 5 & DAMPs $=1$ if (Injury $=1$ AND ROS $=1)$ and $M 2=1$ & $\begin{array}{l}\text { Extensive damage resulting from both injury and ROS in the } \\
\text { presence of } \mathrm{M} 2 \text { is not completely resolved. }\end{array}$ & [85-92] \\
\hline 6 & DAMPs $=2$ if (Injury $=1$ AND ROS $=1)$ and $M 2=0$ & $\begin{array}{l}\text { Excess injury triggers an overwhelming immune response } \\
\text { that destroys the tissue in the absence of M2 macrophages. }\end{array}$ & [85-92] \\
\hline 7 & M1 (3) = 0 if $(C C L 2=0)$ & $\begin{array}{l}\text { Pro-inflammatory cytokines (exemplified by CCL2) are } \\
\text { required to recruit M1 monocytes/macrophages. }\end{array}$ & {$[1,5,67,82-84,93]$} \\
\hline 8 & $M 1=1$ if $C C L 2=1$ & Macrophage recruitment is initiated in response to cytokines. & {$[1,5,67,82-84,93]$} \\
\hline 9 & $\mathrm{M} 1=2 \mathrm{CCL} 2=2$ & increased cytokine levels result in more M1 macrophages. & {$[1,5,67,82-84,93]$} \\
\hline 10 & $M 2(2)=1$ if $M 1=1$ & M1 macrophages differentiate into M2. & {$[1,5,67,82-84,93]$} \\
\hline 11 & M2 $=0$ otherwise & $\begin{array}{l}\text { M1s must exist to differentiate into M2s; and overwhelming } \\
\text { M1 infiltration overcomes M2. }\end{array}$ & {$[1,5,67,82-84,93]$} \\
\hline \multicolumn{4}{|c|}{ Intracellular scale rules } \\
\hline \multicolumn{4}{|c|}{ DAMPs and $\mathrm{M} 2<-$ from tissue model } \\
\hline 12 & $\operatorname{CD} 13(2)^{*}=1$ if DAMPs $=1$ or 2 & CD13 is phosphorylated upon ligand binding to TLR4 & {$[49,71,94]$} \\
\hline 13 & CD13 $=0$ otherwise & CD13 is not activated without inflammation & {$[49]$} \\
\hline 14 & $\operatorname{TRIF}(3)=0$ if DAMPs $=0$ regardless of CD13 & There is no response without tissue damage. & {$[25,49,95]$} \\
\hline 15 & TRIF $=1$ if $($ DAMPs $=1)$ and $(C D 13=1)$ & Ligation and endocytosis of TLR4 triggers TRIF activation. & {$[25,49,95]$} \\
\hline 16 & $\mathrm{TRIF}=2$ if $(\mathrm{DAMPs}=1)$ and $(\mathrm{CD} 13=0)$ & TRIF is hyper-activated in the absence of CD13 & {$[25,49,95]$} \\
\hline 17 & $\mathrm{TRIF}=2$ if $\mathrm{DAMPs}=2$ regardless of $\mathrm{CD} 13$ & Excess injury triggers an overwhelming immune response. & {$[25,49,95]$} \\
\hline 18 & IRF3 (3) = TRIF (3) & TRIF activates IRF3 & {$[25,49,95]$} \\
\hline 19 & $\mathrm{IFN}-\beta(3)=\mathrm{IRF} 3$ & Active IRF3 transcriptionally activates IFN- $\beta$ & {$[19,49,73,96,97]$} \\
\hline 18 & $\operatorname{ROS}(2)=1$ IFN $\beta=2->$ to intracellular model & High levels of IFN- $\beta$ induce ROS & {$[49,87,88,90-92]$} \\
\hline 19 & $\mathrm{ROS}=0$ otherwise & Low levels of IFN- $\beta$ do not induce ROS. & {$[49,87,88,90-92]$} \\
\hline 20 & MyD88 = DAMPs (3) & DAMPs bind TLR4 and activate MyD88 from the cell surface. & {$[98-100]$} \\
\hline 21 & pIRAK = MyD88 (3) & Activated MyD88 enables IRAK phosphorylation/activation. & {$[98-100]$} \\
\hline 22 & $N F-k B=0$ if $M 2=1$ and $(p \mid R A K=0$ or 1$)$ & $\begin{array}{l}\text { M2 macrophages dampen NF-kB activity and halt inflammation } \\
\text { unless overwhelming response. }\end{array}$ & {$[98-100]$} \\
\hline 23 & $N F-k B=p I R A K(3)$ otherwise & pIRAK activates NF-kB. & {$[67,93]$} \\
\hline 24 & $\mathrm{CCL} 2=\mathrm{NF}-\mathrm{kB}(3)$ & NF-kB transcriptionally regulates CCL2 & {$[98-100]$} \\
\hline
\end{tabular}

*\# of states for the node; **XOR - either or

CCL2 and ROS - > to tissue scale

endosomal vesicles [57]. Positive and negative regulators of this process exist and represent additional nodes for future inclusion $[58,59]$. This pathway involves the TRIF (TIR domain-containing adaptor protein-inducing IFN$\beta$ ) adaptors to activate the interferon regulatory factors, IRFs (Interferon Regulatory Factors), a family of transcription factors that are important in antiviral defense, cell growth and immune regulation. One of these, IRF3, stimulates production of the type I interferons, IFN- $\alpha$ and $-\beta$ (designated as IFN- $\beta$ ). IFN binding to IFNAR (the IFN- $\alpha$ and $-\beta$ receptor, not included as a node) induces signal transduction to initiate production of iNOS, the enzyme responsible for the formation of bactericidal reactive oxygen species (ROS). While the secreted extracellular ROS are critical to microbial defense, these can be toxic when present at high levels and lead to further tissue injury, cell death, increased release of DAMPs and recruitment of monocytes/macrophages in the tissue via the TLR4/MyD88/CCL2 pathway [60-63]. The hyperactivated state of this MyD88-independent 
Table 3 TRIF depends on DAMPs and CD13

\begin{tabular}{lll}
\hline Possible input configurations & & State values \\
\hline DAMPs & CD13 & TRIF \\
\hline 0 & 0 & 0 \\
0 & 1 & 0 \\
1 & 0 & 2 \\
1 & 1 & 1 \\
2 & 0 & 2 \\
2 & 1 & 1 \\
\hline
\end{tabular}

pathway (IFN- $\beta=2)$ triggers ROS, while normal response to injury produces IFN- $\beta$ but no ROS. We have assigned three levels of activation to TRIF, IRF3, $\operatorname{IFN}-\beta(0,1,2)$ and two to ROS $(0,1)$, Table 2 . Rules \#14-19. Finally, this pathway also triggers a distinct, delayed alternate pathway to NF- $\mathrm{kB}$ activation [53] which we have not included in this acute model.

\section{Tissue injury resolution or further damage}

Cytokines produced intracellularly are secreted into the tissue where they activate endothelial cells lining adjacent blood vessels to attract additional circulating monocytes into the site of injury to enhance the response [64]. We assume in the model that these cytokines are initially produced by tissue-resident macrophages and subsequently by recruited, infiltrating M1 macrophages (Table 2, rules \#7-9). Once in the tissue, monocytes differentiate into M1 macrophages that ingest and degrade the DAMPs and digest the extracellular matrix to allow fibrosis, development of granulation tissue and the eventual scar $[65,66]$. Reduced DAMPs levels prompt a second, pro-resolution phase where M1 macrophages switch to an M2 phenotype (rules \# 10, 11, refs [5, 11, 16, 67, 68]). M2 macrophages contain fewer inflammatory molecules and proteases and elicit factors that promote angiogenesis and collagen deposition as well as reduce inflammation by downregulating intracellular NF-kB activity and CCL2 production (Table 2, rules \#1, 22 and 24, ref. [67]). A systemic lack of monocytes/macrophages leads to persistence of DAMPs, increased overall cytotoxic TLR4 signaling, lack of M2 macrophages and further damage [69]. Similarly, a lack of M2 macrophages also leads to persistent DAMPs, excess inflammatory cytokines, damaging oxidative stress and ROS production [70]. (Table 2, rules \#3-6).

\section{CD13 in TLR4 signaling}

We have demonstrated that a lack of CD13 increases TLR4 MyD88-independent signaling by virtue of its endocytic regulatory properties [49]. We have also shown that CD13 is phosphorylated upon ligand binding, which is required for its effects on receptor uptake
$[49,71]$. This rise in ligand-receptor internalization enhances activation of the MyD88-independent endosomal-signaling arm of the TLR4 response, leading to aberrantly high levels of type I interferons and ultimately production of injurious reactive oxygen species (ROS), thus exacerbating injury due to inflammation. We have incorporated results from this study into the model, where CD13 $=0$ when unphosphorylated/inactive, or $\mathrm{CD} 13=1$ when phosphorylated/activated (Table 2, Rules \#12-17).

\section{Model simulation}

Below we describe the results of a model analysis and validation by comparing its behavior under certain perturbations with known, previously published in vivo results from knockout animal studies (references listed in Table 6). Interrogation of the model is through simulation. The model is first initialized with all possible state values for each of the nodes, (e.g. Injury $=0,1, \mathrm{DAMPs}=0,1,2$, etc.). We then apply the rules in Table 2 to each of the model nodes to obtain the new state value for each node according to our rules. Further iteration provides a chronological time course of states, which can either terminate in a steady state or a periodic repeated pattern or 'limit cycle'. For our model, all time courses terminate in a steady state. However, since the model integrates two different spatial scales and consequently, two different temporal scales, we needed to modify the scheme by which the nodes are updated. Since we assume the intracellular scale will be significantly faster than the tissue scale, we have designed the update scheme as follows: for a given initialization for all nodes, we first combine the nodes from the intracellular model, the two input nodes DAMPs and M2 and the two output nodes ROS and CCL2 and together consider them as a separate model. We then iterate this sub-model until it reaches a steady state. The steady state values that are obtained for the two output nodes are assigned as initialization values for the tissue level nodes to enter into the rule simulation. The new values of the tissue-level nodes reached at the end of the simulation, merged with the steady state values of the cell model, then comprise the state of the entire model at the next time step. This scheme is illustrated with an example in Fig. 3.

\section{Model analysis}

The initial model analysis below was obtained by exhaustively simulating the model by computing the transition for each possible configuration of node values, using the software package PlantSimLab (http://app. plantsimlab.org). In this way we can determine all possible steady states of the model, which can be interpreted as all the possible outcomes of the response to injury when all possible configurations of the underlying network are considered. We then determine how often 


\begin{tabular}{|c|c|c|c|c|c|c|c|c|c|c|c|c|c|}
\hline \multirow{3}{*}{ Model state at time $t$} & \multicolumn{7}{|c|}{ Intracellular nodes } & \multicolumn{6}{|c|}{ Tissue nodes } \\
\hline & TRIF & CD13 & IRF3 & IFNb & MyD88 & 8 pIRAK & NF-kB & DAMPs & \begin{tabular}{l|l}
$\mathrm{s}$ & $\mathrm{M} 2$
\end{tabular} & ROS & $\mathrm{CCL} 2$ & M1 & Injury \\
\hline & 1 & 1 & 0 & 0 & 2 & 1 & 2 & 2 & 0 & 1 & 0 & 0 & 1 \\
\hline \multicolumn{14}{|c|}{ Intracellular model iterations } \\
\hline \multirow{2}{*}{ Intracellular steady state } & & TRIF & CD13 & IRF3 & IFNb & MyD88 & PIRAK & NF-kB & DAMPs & M2 & ROS & CCL2 & \\
\hline & & 2 & 1 & 2 & 2 & 2 & 2 & 2 & 2 & 0 & 1 & 2 & \\
\hline \multirow{2}{*}{ Model state at time $t+1$} & TRIF & CD13 & IRF3 & IFNb & MyD88 & PIRAK & NF-kB & DAMPs & s $\quad$ M2 & ROS & CCL2 & M1 & Injury \\
\hline & 2 & 1 & 2 & 2 & 2 & 2 & 2 & 2 & 0 & 1 & 2 & 1 & 1 \\
\hline
\end{tabular}

(\% of total) each input leads to a particular steady state/ outcome, also known as the 'basin of attraction', thus providing a measure of how likely the different outcomes are. For clarity, we have listed the outcomes for the intracellular and tissue components of the model separately (Tables 4, 5, 6 and 7).

In (Table 4) we initiate the intracellular model from all possible initial state values for our input nodes, DAMPs and M2 (Table 4, columns a and b). Simulations result in six possible steady states with identical basin of attraction sizes. Steady states \#1 and 2 of Table 4 portray the intracellular response when there is either no injury or injury has been resolved. Steady states \#3 and 4 describe the chronic response to initial injury and, finally, steady states \#5 and 6 describe the states where high levels of cytokines and ROS lead to overwhelming inflammation and cell death. Tables 5 and 6 are transition tables detailing how values are generated by the intracellular model for the input nodes CCL2 and ROS. We used these values then to initiate the tissue model
(Table 7). This simulation of the intracellular-level model results in a dominant steady state, \#1 (92.6\%) that describes the tissue with low levels of DAMPs and macrophages as would result with either no injury or injury followed by resolution (Table 7). In comparison, steady state \#2 is a state with a small basin of attraction (5.6\%), that is, a steady state observed rarely, that represents an overwhelming inflammatory response triggered by injury with high levels of cytokine production, ROS and cell death, as demonstrated by maximal levels of all proinflammatory components and ROS. Finally, since the simulation software initializes from all possible values, it can produce biologically improbable steady states as in steady state \#3 where ROS is present with no injury (Table 7). This is reflected by the fact that the basin of attraction for this steady state only contains less than $2 \%$ of all possible model initializations. Essentially, the DAMPs and M2 values from the intracellular model (Table 4) are also, indirectly, the initial 'input' values for the tissue-level model (Table 7)

Table 4 Intracellular scale steady states

\begin{tabular}{|c|c|c|c|c|c|c|c|c|c|c|c|c|}
\hline & \multicolumn{2}{|c|}{ Initial inputs } & \multirow[b]{2}{*}{ c } & \multirow[b]{2}{*}{$d$} & \multirow[b]{2}{*}{ e } & \multirow[b]{2}{*}{$f$} & \multirow[b]{2}{*}{ g } & \multirow[b]{2}{*}{ h } & \multirow[b]{2}{*}{ i } & \multirow[b]{2}{*}{ j } & \multirow[b]{2}{*}{ k } & \multirow[b]{2}{*}{ I } \\
\hline & a & $b$ & & & & & & & & & & \\
\hline & DAMPs(3) & M2(2) & $\operatorname{ROS}(2)$ & CCL2(3) & $\operatorname{TRIF(3)}$ & CD13(2) & IRF3(3) & INFb(3) & MyD88(3) & $\operatorname{pIRAK}(3)$ & NF-kB(3) & basin of attraction \\
\hline Steady State 1 & 0 & 0 & 0 & 0 & 0 & 0 & 0 & 0 & 0 & 0 & 0 & $16.66 \%$ \\
\hline Steady State 2 & 0 & 1 & 0 & 0 & 0 & 0 & 0 & 0 & 0 & 0 & 0 & $16.66 \%$ \\
\hline Steady State 3 & 1 & 0 & 0 & 1 & 1 & 1 & 1 & 1 & 1 & 1 & 1 & $16.66 \%$ \\
\hline Steady State 4 & 1 & 1 & 0 & 0 & 1 & 1 & 1 & 1 & 1 & 1 & 0 & $16.66 \%$ \\
\hline Steady State 5 & 2 & 0 & 1 & 2 & 2 & 1 & 2 & 2 & 2 & 2 & 2 & $16.66 \%$ \\
\hline Steady State 6 & 2 & 1 & 1 & 2 & 2 & 1 & 2 & 2 & 2 & 2 & 2 & $16.66 \%$ \\
\hline
\end{tabular}


Table 5 Transition table generating values for ROS in the tissue-level model based on columns a (DAMPs) and c (ROS) of Table 4

\begin{tabular}{ll}
\hline Input configuration for DAMPs & Outcome/state value for ROS \\
\hline 0 & 0 \\
1 & 0 \\
2 & 1 \\
\hline
\end{tabular}

since they ultimately determine the ROS and CCL2 steady state values that drive the intracellular-level model. A flow chart depicting the inputs and outcomes of the model is shown in Fig. 4.

\section{Model validation}

To verify that the model captures some key features of the injury response, we considered published studies of injury models in wild type animals and those engineered to lack one of five different nodes in our model and interpreted the phenotypes in light of our model behavior [1, 49, 51, 54, 55, 72-78]. Similar to simulations of the wild type models, we initially computed the steady state values for each intracellular component from all possible initializations with the specific node knocked out (essentially set to 0 ), represented by the numbers in each row (Table 8). These intracellular steady state values were then assigned as input values to initialize the tissue model and then we determined the values at which the output converged (the steady state) as described below.

\section{Analysis of intracellular and tissue states}

Wild type, TRIF knockout, and CD13 knockout The states in each of these simulations converge to steady states in the intracellular model which correspond to states in the tissue model that proceed to resolution (Steady state 1, Table 7), in agreement with the tissue states.

MyD88, IRAK, and CCL2 knockouts The intracellular states lack input values for M2 and so we simulated both possible input values, 0 and 1 , (Table 8 ). When $\mathrm{M} 2=0$,

Table 6 Transition table for CCL2 in the tissue-level model based on columns a (DAMPs), b (M2), and d (CCL2) of Table 4

\begin{tabular}{lll}
\hline Input configurations & Outcome value \\
${ } }$ & M2 & CCL2 \\
\hline 0 & 0 or 1 & 0 \\
1 & 0 & 1 \\
1 & 1 & 0 \\
2 & 0 or 1 & 2 \\
\hline
\end{tabular}

the given state is a steady state itself and when input into the tissue model, it converges to steady state \#3 (Table 7), where injury fails to resolve as resulted from the absence of M2. If we initialize the tissue model with all six possible combinations of the missing values it converges to two steady states (Table 8$)$. In two of the six cases (33\%), when we assign $(M 1, M 2)=(0,0)$ and $(2,0)$, injury is not resolved since DAMPs converge to $=1$ (steady state \#3 in the simulation). For the other four $(66 \%$, Table 8$)$ of the possible values of $\mathrm{M} 1$ and $\mathrm{M} 2,(0,1),(1,1),(0,0)$ and $(2$, $1)$, the states converge to the largest steady state (steady state \#1, Table 7) where injury is resolved, suggesting that the injury will eventually resolve unless M2 macrophages are absent, or 0 .

TRIF knockout The values for M1 and M2 are again missing but all possible combinations of values give states that are in the largest steady state (steady state \#1, Table 7), where injury is resolved. Taken together, the model we have constructed essentially resolves the injury despite perturbation with the exception of the absence of M2 macrophages. Since M2 cells are the progeny of M1 macrophages [5, 11, 16, 67, 68], the scenario where M1 is assigned as 0 and M2 as 1 is biologically impossible. Therefore, it can be assumed that the absence of M1 macrophages will also be considered to result in failure to resolve injury.

\section{Reconciliation with published studies}

While we consider the results of the simulation to be consistent with the known experimental results, we are aware that states in Table 8 do not necessarily match the published results of the in vivo experiments, but rather represent the steady states to which these biological systems would be expected to eventually converge. For example, experiments evaluating the response at 3-5d post injury during the inflammatory phase in the absence of the MyD88-dependent pathway generally report reduced inflammation [29, 30]. By contrast, interruption of the MyD88-independent pathway injury produces a proinflammatory, high damage state despite the absence of ROS, suggesting that the MyD88-dependent pathway contributes to inflammation-induced damage to a greater extent than the MyD88-independent pathway [73]. However, these experimental measurements are not taken at the point of equilibrium, but at defined time points (days post-injury) where the system is actively working toward resolving the injury. Therefore this is not a shortcoming of the model, but confirms that the model captures the most crucial features of the biological system.

\section{Discussion and Conclusions}

We have constructed a basic logical model of inflammatory signaling and monocyte trafficking in response to 
Table 7 Tissue scale steady states

\begin{tabular}{llllllll}
\hline & 1 & 2 & 3 & 4 & 5 & 6 & \\
& DAMPs(3) & M1(3) & M2(2) & Injury(2) & ROS(2) & CCL2(3) & Basin of attraction \\
\hline Steady State 1 & 0 & 0 & 0 & 0 & 0 & 0 & $92.59 \%$ \\
Steady State 2 & 2 & 2 & 0 & 1 & 1 & 2 & $5.55 \%$ \\
Steady State 3 & 2 & 2 & 0 & 0 & 1 & 2 & $1.85 \%$ \\
\hline
\end{tabular}

acute, sterile tissue injury that faithfully recapitulates components of published in vivo knockout experiments. Reconciling computational models with experimental data is difficult for a number of reasons. Biologists perturb systems with the goal of determining the intermediate steps that the system undergoes to achieve the steady state, in this case healing. Therefore data are collected on defined nodes at various time intervals following initiation of the experiment and rarely at a steady state. On the other hand, computational models test nearly every possible combination of input values and converge on a steady state that can be considered as the long-term outcome of tissue injury. In the case of the fully functioning system in wild type animals, the damage is eventually resolved, and the intermediate steps proceed to the steady state of healing. In the case of loss of one of the nodes of the system, the model is perturbed, but eventually converges to resolution.

To this point, we have not modeled fibrosis and scarring which are often exacerbated when inflammation is dysregulated and can severely impact functional recovery of the tissue following ischemic injury. Including these processes in the model would likely capture the impairment of tissue function that persists following the resolution of inflammation in a compromised host.

We developed the current model as a basis for constructing a larger, more complex network model that can be used to predict the inflammatory response to

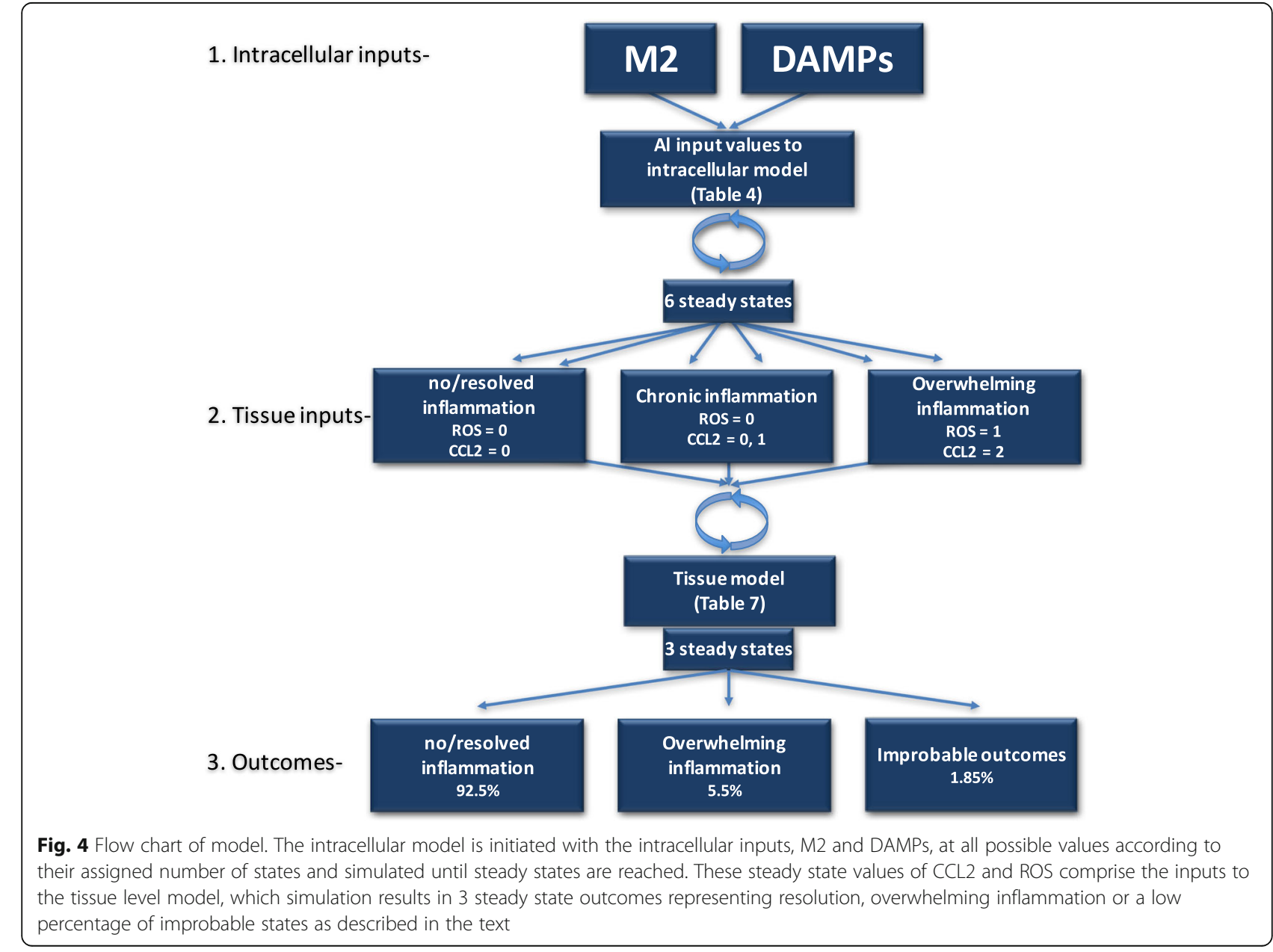


Table 8 Verification of the model based on results from published studies

\begin{tabular}{|c|c|c|c|c|c|c|c|c|c|c|c|c|c|c|c|c|}
\hline & DAMPS & M1 & M2 & ROS & CCL2 & TRIF & CD13 & IRF3 & INFb & MyD88 & pIRAK & NF- kB & $\begin{array}{l}\text { Intracellular } \\
\text { steady state } \\
\text { (from Table 4) }\end{array}$ & $\begin{array}{l}\text { Tissue steady } \\
\text { state (from } \\
\text { Table } 7 \text { ) }\end{array}$ & $\begin{array}{l}* * * \% \text { injury } \\
\text { resolved or } \\
\text { unresolved }\end{array}$ & references \\
\hline$\overline{W T}$ & 2 & 1 & 1 & 0 & 1 & 1 & 1 & 1 & 1 & 1 & 1 & 1 & 6 & 1 & $100 \%-0 \%$ & [49] \\
\hline MyD88 KO & 1 & ND & ND & 0 & 0 & ND & 1 & ND & ND & & 0 & 0 & 3 or 4 & 1 or $3^{*}$ & $66 \%-33 \%$ & {$[72,73]$} \\
\hline IRAK KO & 1 & ND & ND & 0 & 0 & 1 & 1 & ND & ND & 1 & - & 0 & 3 or 4 & 1 or $3^{*}$ & $66 \%-33 \%$ & [74-76] \\
\hline CCL2 KO & 1 & ND & ND & 0 & - & 1 & 1 & ND & ND & 1 & 1 & 1 & 3 or 4 & 1 or $3^{*}$ & $66 \%-33 \%$ & {$[54,55]$} \\
\hline TRIF KO & 1 & ND & ND & 0 & 1 & - & 1 & 0 & 0 & 1 & 1 & 1 & 6 & $1^{* *}$ & 100\%-0\% & {$[51,73]$} \\
\hline $\mathrm{CD} 13 \mathrm{KO}$ & 2 & 1 & 1 & 1 & 1 & 2 & & 2 & 2 & 1 & 1 & 1 & 6 & 1 & $100 \%-0 \%$ & [49] \\
\hline
\end{tabular}

$N D$ values not empirically determined in published studies

* Values not empirically determined for $M 1$ and $M 2$ : When we set $(M 1, M 2)=(0,0)$ and $(2,0)$, injury is not resolved as the states result in tissue steady state 3

(Table 7) where DAMPs is at MEDIUM (33\%). For the other four possible values of $\mathrm{MI}$ and $\mathrm{M} 2$, the states result in tissue steady state 1 from Table 7 where injury is resolved (DAMPs is LOW, 66\%)

** Values not determined for M1 and M2: Assigning all possible combinations (100\%) of the missing values result in the largest steady state (steady state 1) where injury is resolved

*** indication of \% injury resolved or unresolved resulting from assigning all possible values for undetermined nodes as explained in * and **

different stimuli, additional receptors, cytokines, control points and cell types. For example, neutrophils are a critical component of the inflammatory response and neutropenia results in recurrent infections and impaired healing [8]. In addition, while we have included CD13 as a negative regulator of the MyD88-independent response, additional control nodes such as ATF3 (induces a negative feedback loop [58]) or the positive regulator CD14 (required for MyD88-independent signaling) could be added [59]. Alternatively, a component of gram negative bacterial cell walls triggers the same responses that we have modeled in response to injury. However, recurrent bacterial infections produce antibodies that bind to the bacteria, thereby creating a dual stimulus for the cell (via TLR4 and FCRs) to elicit a combined immune response considerably different from that initiated by either receptor alone and more efficient at triggering both innate and adaptive immunity $[79,80]$. Mathematical modeling of such altered responses could lead to the identification of novel convergence nodes as therapeutic targets for inflammatory and autoimmune diseases.

A significant limitation of the current model is that it does not account for the fact that conditions in the tissue are not homogeneous so that the inputs to the intracellular component of the model vary across the tissue. In further work, we plan to construct a spatially heterogeneous, agent-based model for the tissue scale, where each monocyte or other immune cell 'agent' is equipped with its own intracellular network that can respond properly to local tissue conditions [81].

\section{Acknowledgements}

We thank Charan Devarakonda and Mallika Ghosh for helpful discussions.

Funding

NHLBI R01 127449 to LHS.

Availability of data and materials

Not applicable.

\section{Authors' contributions}

$E D, L A C, R L$ and LHS participated in formulating the model, ED performed simulations, LAC and LHS provided validation data, ED, LHS and RL wrote the manuscript. All authors read and approved the final manuscript.

Ethics approval and consent to participate

Not applicable.

Consent for publication

Not applicable.

Competing interests

The authors declare that they have no competing interests.

\section{Publisher's Note}

Springer Nature remains neutral with regard to jurisdictional claims in published maps and institutional affiliations.

\section{Author details}

'Department of Mathematical Sciences, Clemson University, Clemson, SC, USA. ${ }^{2}$ Center for Quantitative Medicine, Department of Cell Biology, University of Connecticut School of Medicine, Farmington, CT, USA. ${ }^{3}$ Jackson Laboratory for Genomic Medicine, Farmington, CT, USA. ${ }^{4}$ Center for Vascular Biology, Department of Cell Biology, University of Connecticut School of Medicine, Farmington 06030, CT, USA.

Received: 9 October 2017 Accepted: 28 March 2018

Published online: 10 April 2018

\section{References}

1. van Amerongen MJ, Harmsen MC, van Rooijen N, Petersen AH, van Luyn MJ. Macrophage depletion impairs wound healing and increases left ventricular remodeling after myocardial injury in mice. Am J Pathol. 2007; 170(3):818-29.

2. Auffray C, Fogg D, Garfa M, Elain G, Join-Lambert O, Kayal S, Sarnacki S, Cumano A, Lauvau G, Geissmann F. Monitoring of blood vessels and tissues by a population of monocytes with patrolling behavior. Science. 2007; 317(5838):666-70.

3. Mosser DM. The many faces of macrophage activation. J Leukoc Biol. 2003; 73(2):209-12.

4. Shireman PK. The chemokine system in arteriogenesis and hind limb ischemia. J Vasc Surg. 2007;45(6, Supplement):A48-56.

5. Geissmann F, Mass E. A stratified myeloid system, the challenge of understanding macrophage diversity. Semin Immunol. 2015;27(6):353-6.

6. Swirski FK, Robbins CS, Nahrendorf M. Development and function of arterial and cardiac macrophages. Trends Immunol. 2016;37(1):32-40.

7. Kubes P. The enigmatic neutrophil: what we do not know. Cell Tissue Res. 2018;371(3):399-406 
8. Kolaczkowska E, Kubes P. Neutrophil recruitment and function in health and inflammation. Nat Rev Immunol. 2013;13(3):159-75.

9. Jassam YN, Izzy S, Whalen M, McGavern DB, El Khoury J. Neuroimmunology of traumatic brain injury: time for a paradigm shift. Neuron. 2017;95(6): 1246-65.

10. Arnold L, Henry A, Poron F, Baba-Amer Y, van Rooijen N, Plonquet A, Gherardi RK, Chazaud B. Inflammatory monocytes recruited after skeletal muscle injury switch into antiinflammatory macrophages to support myogenesis. J Exp Med. 2007;204(5):1057-69.

11. Zhou D, Huang C, Lin Z, Zhan S, Kong L, Fang C, Li J. Macrophage polarization and function with emphasis on the evolving roles of coordinated regulation of cellular signaling pathways. Cell Signal. 2014;26(2):192-7.

12. Perdiguero $E$, Sousa-Victor $P$, Ruiz-Bonilla V, Jardi M, Caelles C, Serrano AL, Munoz-Canoves P. p38/MKP-1-regulated AKT coordinates macrophage transitions and resolution of inflammation during tissue repair. J Cell Biol. 2011;195(2):307-22.

13. Daley JM, Reichner JS, Mahoney EJ, Manfield L, Henry WL Jr, Mastrofrancesco B, Albina JE. Modulation of macrophage phenotype by soluble product(s) released from neutrophils. J Immunol. 2005;174(4):2265-72.

14. Wehner S, Buchholz BM, Schuchtrup S, Rocke A, Schaefer N, Lysson M, Hirner A, Kalff JC. Mechanical strain and TLR4 synergistically induce cellspecific inflammatory gene expression in intestinal smooth muscle cells and peritoneal macrophages. Am J Physiol Gastrointest Liver Physiol. 2010; 299(5):G1187-97.

15. Blakney AK, Swartzlander MD, Bryant SJ. The effects of substrate stiffness on the in vitro activation of macrophages and in vivo host response to poly(ethylene glycol)-based hydrogels. J Biomed Mater Res A. 2012;100(6): 1375-86.

16. Murray PJ, Allen JE, Biswas SK, Fisher EA, Gilroy DW, Goerdt S, Gordon S, Hamilton JA, Ivashkiv LB, Lawrence T, et al. Macrophage activation and polarization: nomenclature and experimental guidelines. Immunity. 2014; 41(1):14-20.

17. Kim M-G, Su Boo C, Sook Ko Y, Young Lee H, Yong Cho W, Kyu Kim H, Jo S-K. Depletion of kidney CD11C+ F4/80+ cells impairs the recovery process in ischaemia/reperfusion-induced acute kidney injury. Nephrology Dialysis Transplantation. 25(9):2908-21.

18. Hirose N, Maeda H, Yamamoto M, Hayashi Y, Lee G-H, Chen L, Radhakrishnan G, Rao P, Sasaguri S. The local injection of peritoneal macrophages induces neovascularization in rat ischemic hind limb muscles. Cell Transplant. 2008; 17(1-2):211-22.

19. Sachdev U, Cui X, Tzeng E. HMGB1 and TLR4 mediate skeletal muscle recovery in a murine model of hindlimb ischemia. J Vasc Surg. 2013

20. Feng $Y$, Zhao H, Xu X, Buys ES, Raher MJ, Bopassa JC, Thibault H, ScherrerCrosbie M, Schmidt U, Chao W. Innate immune adaptor MyD88 mediates neutrophil recruitment and myocardial injury after ischemia-reperfusion in mice. Am J Phys Heart Circ Phys. 2008;295(3):H1311-h1318.

21. Caso JR, Pradillo JM, Hurtado O, Lorenzo P, Moro MA, Lizasoain I. Toll-like receptor 4 is involved in brain damage and inflammation after experimental stroke. Circulation. 2007;115(12):1599-608.

22. Haeusler KG, Schmidt WU, Foehring F, Meisel C, Guenther C, Brunecker P, Kunze C, Helms T, Dirnagl U, Volk HD, et al. Immune responses after acute ischemic stroke or myocardial infarction. Int J Cardiol. 2012;155(3):372-7.

23. Rosadini CV, Kagan JC. Early innate immune responses to bacterial LPS. Curr Opin Immunol. 2017:44:14-9.

24. Yang $\mathrm{H}$, Wang $\mathrm{H}$, Chavan SS, Andersson U. High mobility group box protein 1 (HMGB1): the prototypical endogenous danger molecule. Molecular medicine (Cambridge, Mass). 2015;21(Suppl 1):S6-s12.

25. Palsson-McDermott EM, O'Neill LA. Signal transduction by the lipopolysaccharide receptor, toll-like receptor-4. Immunology. 2004;113(2):153-62.

26. Namas RA, Mi Q, Namas R, Almahmoud K, Zaaqoq AM, Abdul-Malak O, Azhar N, Day J, Abboud A, Zamora R, et al. Insights into the role of chemokines, damage-associated molecular patterns, and lymphocyte-derived mediators from computational models of trauma-induced inflammation. Antioxid Redox Signal. 2015;23(17):1370-87.

27. Billiar TR, Vodovotz Y. Time for trauma immunology. PLoS Med. 2017;14(7): e1002342.

28. Laubenbacher R, Stigler B. A computational algebra approach to the reverse engineering of gene regulatory networks. J Theor Biol. 2004;229(4):523-37.

29. Albert $\mathrm{R}$, Othmer $\mathrm{HG}$. The topology of the regulatory interactions predicts the expression pattern of the segment polarity genes in Drosophila melanogaster. J Theor Biol. 2003;223(1):1-18.
30. Davidson EH, Rast JP, Oliveri P, Ransick A, Calestani C, Yuh CH, Minokawa T, Amore G, Hinman V, Arenas-Mena C, et al. A genomic regulatory network for development. Science. 2002;295(5560):1669-78.

31. Thomas R. Regulatory networks seen as asynchronous automata: a logical description. J Theor Biol. 1991;153(1):1-23.

32. Veliz-Cuba A, Stigler B. Boolean models can explain bistability in the lac operon. J Comput Biol. 2011;18(6):783-94.

33. Guo Y, Wang P, Gui W, Yang C. Set stability and set stabilization of Boolean control networks based on invariant subsets. Automatica. 2015; 61:106-12.

34. Wei XN, Han BC, Zhang JX, Liu XH, Tan CY, Jiang YY, Low BC, Tidor B, Chen $Y Z$. An integrated mathematical model of thrombin-, histamine-and VEGFmediated signalling in endothelial permeability. BMC Syst Biol. 2011;5:112.

35. Forsten-Williams K, Kurtagic E, Nugent MA. Complex receptor-ligand dynamics control the response of the VEGF system to protease injury. BMC Syst Biol. 2011;5:170

36. Johnson CD, Balagurunathan $Y$, Dougherty ER, Afshari CA, He Q, Ramos KS. Insight into redox-regulated gene networks in vascular cells. Bioinformation. 2007;1(10):379-83.

37. Roberts BN, Christini DJ. The relative influences of phosphometabolites and $\mathrm{pH}$ on action potential morphology during myocardial reperfusion: a simulation study. PLoS One. 2012;7(11):e47117.

38. Liu Y, Buerk DG, Barbee KA, Jaron D. Nitric oxide release by deoxymyoglobin nitrite reduction during cardiac ischemia: a mathematical model. Microvasc Res. 2017;112:79-86.

39. Liu Y, Buerk DG, Barbee KA, Jaron D. A mathematical model for the role of $\mathrm{N} 2 \mathrm{O} 3$ in enhancing nitric oxide bioavailability following nitrite infusion. Nitric Oxide. 2016;60:1-9.

40. Budu-Grajdeanu P, Schugart RC, Friedman A, Valentine C, Agarwal AK, Rovin BH. A mathematical model of venous neointimal hyperplasia formation. Theor Biol Med Model. 2008;5:2.

41. Mohamed Mokhtarudin MJ, Payne SJ. Mathematical model of the effect of ischemia-reperfusion on brain capillary collapse and tissue swelling. Math Biosci. 2015;263:111-20.

42. Guerreiro-Lucas LA, Pop SR, Machado MJ, Ma YL, Waters SL, Richardson G, Saetzler K, Jensen OE, Mitchell CA. Experimental and theoretical modelling of blind-ended vessels within a developing angiogenic plexus. Microvasc Res. 2008;76(3):161-8.

43. Ismailov RM. Arch vessel injury: geometrical considerations. Implications for the mechanism of traumatic myocardial infarction II. World J Emerg Surg. 2006;1:28

44. Schugart RC, Friedman A, Zhao R, Sen CK. Wound angiogenesis as a function of tissue oxygen tension: a mathematical model. Proc Natl Acad Sci U S A. 2008;105(7):2628-33.

45. Leiderman K, Fogelson AL. Grow with the flow: a spatial-temporal model of platelet deposition and blood coagulation under flow. Mathematical medicine and biology : a journal of the IMA. 2011;28(1):47-84.

46. Leiderman K, Fogelson AL. The influence of hindered transport on the development of platelet thrombi under flow. Bull Math Biol. 2013;75(8): 1255-83.

47. Fong $D$, Cummings $L J$. Mathematical modeling of ischemia-reperfusion injury and Postconditioning therapy. Bull Math Biol. 2017;

48. Day JD, Metes DM, Vodovotz Y. Mathematical modeling of early cellular innate and adaptive immune responses to ischemia/reperfusion injury and solid organ Allotransplantation. Front Immunol. 2015;6:484

49. Ghosh M, Subramani J, Rahman MM, Shapiro LH. CD13 restricts TLR4 endocytic signal transduction in inflammation. J Immunol. 2015;194(9):4466-76.

50. Kim S, Kim SY, Pribis JP, Lotze M, Mollen KP, Shapiro R, Loughran P, Scott MJ, Billiar TR. Signaling of high mobility group box 1 (HMGB1) through toll-like receptor 4 in macrophages requires CD14. Molecular medicine (Cambridge, Mass). 2013;19:88-98.

51. Kagan JC, Su T, Horng T, Chow A, Akira S, Medzhitov R. TRAM couples endocytosis of toll-like receptor 4 to the induction of interferon-beta. Nat Immunol. 2008;9(4):361-8.

52. Wang L, Trebicka E, Fu Y, Waggoner L, Akira S, Fitzgerald KA, Kagan JC, Cherayil BJ. Regulation of lipopolysaccharide-induced translation of tumor necrosis factor-alpha by the toll-like receptor 4 adaptor protein TRAM. J Innate Immun. 2010;3(5):437-46.

53. Barton GM, Kagan JC. A cell biological view of toll-like receptor function: regulation through compartmentalization. Nat Rev Immunol. 2009;9(8):535-42. 
54. Mandrekar P, Ambade A, Lim A, Szabo G, Catalano D. An essential role for monocyte chemoattractant protein-1 in alcoholic liver injury: regulation of proinflammatory cytokines and hepatic steatosis in mice. Hepatology. 2011; 54(6):2185-97.

55. Moore LB, Sawyer AJ, Charokopos A, Skokos EA, Kyriakides TR. Loss of monocyte chemoattractant protein-1 alters macrophage polarization and reduces NFkappaB activation in the foreign body response. Acta Biomater. 2015;11:37-47.

56. Mata-Haro V, Cekic C, Martin M, Chilton PM, Casella CR, Mitchell TC. The vaccine adjuvant monophosphoryl lipid a as a TRIF-biased agonist of TLR4. Science. 2007;316(5831):1628-32

57. Mosesson $Y$, Mills GB, Yarden Y. Derailed endocytosis: an emerging feature of cancer. Nat Rev Cancer. 2008:8(11):835-50.

58. Gilchrist M, Thorsson V, Li B, Rust AG, Korb M, Roach JC, Kennedy K, Hai T, Bolouri H, Aderem A. Systems biology approaches identify ATF3 as a negative regulator of toll-like receptor 4. Nature. 2006;441(7090):173-8.

59. Zanoni I, Ostuni R, Marek LR, Barresi S, Barbalat R, Barton GM, Granucci F, Kagan JC. CD14 controls the LPS-induced endocytosis of toll-like receptor 4. Cell. 2011;147(4):868-80.

60. Franzi S, Salajegheh M, Nazareno R, Greenberg SA. Type 1 interferons inhibit myotube formation independently of upregulation of interferon-stimulated gene 15. PLoS One. 2013;8(6):e65362.

61. Nathan C, Ding A. Nonresolving inflammation. Cell. 2010;140(6):871-82.

62. Gutierrez HH, Pitt BR, Schwarz M, Watkins SC, Lowenstein C, Caniggia I, Chumley P. Freeman BA. Pulmonary alveolar epithelial inducible NO synthase gene expression: regulation by inflammatory mediators. Am J Phys. 1995:268(3 Pt 1):L501-8.

63. Jacobs AT, Ignarro LJ. Lipopolysaccharide-induced expression of interferonbeta mediates the timing of inducible nitric-oxide synthase induction in RAW 264.7 macrophages. J Biol Chem. 2001:276(51):47950-7.

64. Muller WA. Leukocyte-endothelial cell interactions in the inflammatory response. Lab Investig. 2002:82(5):521-34.

65. Tidball JG. Mechanisms of muscle injury, repair, and regeneration. Compr Physiol. 2011;1(4):2029-62.

66. Dutta P, Nahrendorf M. Monocytes in myocardial infarction. Arterioscler Thromb Vasc Biol. 2015:35(5):1066-70.

67. Hilgendorf I, Gerhardt LM, Tan TC, Winter C, Holderried TA, Chousterman BG, Iwamoto Y, Liao R, Zirlik A, Scherer-Crosbie M, et al. Ly-6Chigh monocytes depend on $\mathrm{Nr} 4 \mathrm{a} 1$ to balance both inflammatory and reparative phases in the infarcted myocardium. Circ Res. 2014;114(10):1611-22.

68. Novak ML, Koh TJ. Phenotypic transitions of macrophages orchestrate tissue repair. Am J Pathol. 2013;183(5):1352-63.

69. Nahrendorf M, Swirski FK. Monocyte and macrophage heterogeneity in the heart. Circ Res. 2013;112(12):1624-33.

70. Robbins CS, Chudnovskiy A, Rauch PJ, Figueiredo JL, Iwamoto Y, Gorbatov R, Etzrodt M, Weber GF, Ueno T, van Rooijen N, et al. Extramedullary hematopoiesis generates Ly-6C(high) monocytes that infiltrate atherosclerotic lesions. Circulation. 2012;125(2):364-74.

71. Subramani J, Ghosh M, Rahman MM, Caromile LA, Gerber C, Rezaul K, Han DK, Shapiro LH. Tyrosine phosphorylation of CD13 regulates inflammatory cell-cell adhesion and monocyte trafficking. J Immunol. 2013;191(7):3905-12.

72. Kawai T, Adachi O, Ogawa T, Takeda K, Akira S. Unresponsiveness of MyD88deficient mice to endotoxin. Immunity. 1999;11(1):115-22.

73. Wang S, Schmaderer C, Kiss E, Schmidt C, Bonrouhi M, Porubsky S, Gretz N, Schaefer L, Kirschning CJ, Popovic ZV, et al. Recipient toll-like receptors contribute to chronic graft dysfunction by both MyD88- and TRIF-dependent signaling. Dis Model Mech. 2010;3(1-2):92-103.

74. Kawagoe T, Sato S, Matsushita K, Kato H, Matsui K, Kumagai Y, Saitoh T, Kawai T, Takeuchi O, Akira S. Sequential control of toll-like receptordependent responses by IRAK1 and IRAK2. Nat Immunol. 2008;9(6):684-91.

75. Kanakaraj P, Schafer PH, Cavender DE, Wu Y, Ngo K, Grealish PF, Wadsworth SA, Peterson PA, Siekierka JJ, Harris CA, et al. Interleukin (IL)-1 receptor-associated kinase (IRAK) requirement for optimal induction of multiple IL-1 signaling pathways and IL-6 production. J Exp Med. 1998;187(12):2073-9.

76. Thomas JA, Allen JL, Tsen M, Dubnicoff T, Danao J, Liao XC, Cao Z, Wasserman SA. Impaired cytokine signaling in mice lacking the IL-1 receptor-associated kinase. J Immunol. 1999;163(2):978-84.

77. Ko GJ, Boo CS, Jo SK, Cho WY, Kim HK. Macrophages contribute to the development of renal fibrosis following ischaemia/reperfusion-induced acute kidney injury. Nephrol Dial Transplant. 2008;23(3):842-52.
78. Zandbergen HR, Sharma UC, Gupta S, Verjans JW, van den Borne S, Pokhare S, van Brakel T, Duijvestijn A, van Rooijen N, Maessen JG, et al. Macrophage depletion in hypertensive rats accelerates development of cardiomyopathy. J Cardiovasc Pharmacol Ther. 2009:14(1):68-75.

79. den Dunnen J, Vogelpoel LT, Wypych T, Muller FJ, de Boer L, Kuijpers TW, Zaat SA, Kapsenberg ML, de Jong EC. IgG opsonization of bacteria promotes Th17 responses via synergy between TLRs and FcgammaRlla in human dendritic cells. Blood. 2012;120(1):112-21.

80. Bakema JE, Tuk CW, van Vliet SJ, Bruijns SC, Vos JB, Letsiou S, Dijkstra CD, van Kooyk Y, Brenkman AB, van Egmond M. Antibody-opsonized bacteria evoke an inflammatory dendritic cell phenotype and polyfunctional Th cells by cross-talk between TLRs and FCRs. J Immunol. 2015;194(4):1856-66.

81. Oremland M, Michels KR, Bettina AM, Lawrence C, Mehrad B, Laubenbacher R. A computational model of invasive aspergillosis in the lung and the role of iron. BMC Syst Biol. 2016;10:34

82. Nahrendorf M, Swirski FK, Aikawa E, Stangenberg L, Wurdinger T, Figueiredo JL, Libby P, Weissleder R, Pittet MJ. The healing myocardium sequentially mobilizes two monocyte subsets with divergent and complementary functions. J Exp Med. 2007;204(12):3037-47.

83. Swirski FK, Nahrendorf M, Etzrodt M, Wildgruber M, Cortez-Retamozo V, Panizzi P, Figueiredo JL, Kohler RH, Chudnovskiy A, Waterman P, et al. Identification of splenic reservoir monocytes and their deployment to inflammatory sites. Science. 2009;325(5940):612-6.

84. Martin P, Leibovich SJ. Inflammatory cells during wound repair: the good, the bad and the ugly. Trends Cell Biol. 2005;15(11):599-607.

85. Niethammer P. The early wound signals. Curr Opin Genet Dev. 2016:40:17-22.

86. Turner NA. Inflammatory and fibrotic responses of cardiac fibroblasts to myocardial damage associated molecular patterns (DAMPs). J Mol Cell Cardiol. 2016;94:189-200.

87. Ratliff BB, Abdulmahdi W, Pawar R, Wolin MS. Oxidant mechanisms in renal injury and disease. Antioxid Redox Signal. 2016;

88. Halliwell B. Free radicals and vascular disease: how much do we know? BMJ 1993:307(6909):885-6.

89. Fang L, Moore $X L$, Dart AM, Wang LM. Systemic inflammatory response following acute myocardial infarction. Journal of geriatric cardiology : JGC. 2015;12(3):305-12.

90. Mangge H, Becker K, Fuchs D, Gostner JM. Antioxidants, inflammation and cardiovascular disease. World J Cardiol. 2014;6(6):462-77.

91. Chapple IL. Reactive oxygen species and antioxidants in inflammatory diseases. J Clin Periodontol. 1997;24(5):287-96.

92. Gostner JM, Becker K, Fuchs D, Sucher R. Redox regulation of the immune response. Redox Rep. 2013;18(3):88-94.

93. Varga T, Mounier R, Gogolak P, Poliska S, Chazaud B, Nagy L. Tissue LyC6macrophages are generated in the absence of circulating LyC6- monocytes and Nur77 in a model of muscle regeneration. J Immunol. 2013;191(11): 5695-701.

94. Ghosh M, Gerber C, Rahman MM, Vernier KM, Pereira FE, Subramani J, Caromile LA, Shapiro LH. Molecular mechanisms regulating CD13-mediated adhesion. Immunology. 2014;142(4):636-47.

95. Yamamoto M, Sato S, Mori K, Hoshino K, Takeuchi O, Takeda K, Akira S. Cutting edge: a novel toll/IL-1 receptor domain-containing adapter that preferentially activates the IFN-beta promoter in the toll-like receptor signaling. J Immunol. 2002;169(12):6668-72.

96. Au WC, Moore PA, Lowther W, Juang YT, Pitha PM. Identification of a member of the interferon regulatory factor family that binds to the interferon-stimulated response element and activates expression of interferon-induced genes. Proc Natl Acad Sci U S A. 1995:92(25): 11657-61.

97. Schafer SL, Lin R, Moore PA, Hiscott J, Pitha PM. Regulation of type I interferon gene expression by interferon regulatory factor-3. J Biol Chem. 1998:273(5):2714-20.

98. Altemeier WA, Liles WC, Villagra-Garcia A, Matute-Bello G, Glenny RW. Ischemia-reperfusion lung injury is attenuated in MyD88-deficient mice. PLOS One 2013:8(10):e77123.

99. Kenny EF, O'Neill LA. Signalling adaptors used by toll-like receptors: an update. Cytokine. 2008;43(3):342-9.

100. Dupraz P, Cottet S, Hamburger F, Dolci W, Felley-Bosco E, Thorens B. Dominant negative MyD88 proteins inhibit interleukin-1 beta /interferongamma -mediated induction of nuclear factor kappa B-dependent nitrite production and apoptosis in beta cells. J Biol Chem. 2000:275(48):37672-8. 